\title{
A Dual pH-Responsive DOX-Encapsulated Liposome Combined with Glucose Administration Enhanced Therapeutic Efficacy of Chemotherapy for Cancer
}

\author{
Luoping Zhai' \\ Chuangwei Luo' \\ Hannan Gao' \\ Shuaifan Du' \\ Jiyun Shi $\mathbb{D}^{2}$ \\ Fan Wang ${ }^{1-3}$
}

'Medical Isotopes Research Center and Department of Radiation Medicine, School of Basic Medical Sciences, Peking University Health Science Center, Beijing, I00I9I, People's Republic of China; ${ }^{2}$ Key Laboratory of Protein and Peptide Pharmaceuticals, CAS Center for Excellence in Biomacromolecules, Institute of Biophysics, Academy of Sciences, Beijing, I00I0I, People's Republic of China; ${ }^{3}$ Bioland Laboratory (Guangzhou Regenerative Medicine and Health Guangdong Laboratory),

Guangzhou, 510005, People's Republic of China

Correspondence: Fan Wang Medical Isotopes Research Center and Department of Radiation Medicine, School of Basic Medical Sciences, Peking University Health Science Center, Beijing, I00191, People's Republic of China

Email wangfan@bjmu.edu.cn

Jiyun Shi

Key Laboratory of Protein and Peptide Pharmaceuticals, CAS Center for Excellence in Biomacromolecules, Institute of Biophysics, Academy of Sciences, Beijing, I00I0I, People's Republic of China

Email shijiyun@ibp.ac.cn
Background: The acidic microenvironment of cancer can promote tumor metastasis and drug resistance. Acidic tumor microenvironment-targeted therapy is currently an important means for treating tumors, inhibiting metastasis, and overcoming drug resistance. In this study, a dual pH-responsive DOX-encapsulated liposome (DOPE-DVar7-lip@DOX) was designed and fabricated for targeting the acidic tumor microenvironment. On the one hand, the response of acid-sensitive peptide (DVar7) to the acidic tumor microenvironment increased the uptake of liposomes in tumors and prolonged the retention time; on the other hand, the response of acid-sensitive phospholipid (DOPE) to the acidic tumor microenvironment improved the controlled release of DOX in tumors.

Methods: The acid-sensitive peptide DVar7 modified liposomes can be obtained by simple incubation of DSPE-DVar7 with DOX-loaded DOPE liposomes (DOPE-lip@DOX). The tumor targeting of the dual $\mathrm{pH}$-responsive liposome was investigated in vitro and in vivo by near-infrared fluorescence imaging. The tumor therapeutic efficacy of DOPE-DVar7lip@DOX was evaluated in breast cancer mouse model using the traditional liposome as a control. Moreover, we regulated the tumor microenvironment acidity by injecting glucose to further enhance the therapeutic efficacy of cancer.

Results: DVar7 can allosterically insert into the tumor cell membrane in the acidic tumor microenvironment to enhance the tumor uptake of liposomes and prolong the retention time of liposomes in tumor. In addition, the therapeutic efficacy of $\mathrm{pH}$-responsive liposomes can be further enhanced by glucose injection regulating the acidity of tumor microenvironment. Discussion: DVar7 modified acid-sensitive nanocarriers combined with acidity regulation have great potential to improve drug resistance in clinical practice, thus improving the response rate and therapeutic effect of chemotherapy.

Keywords: dual pH-responsive, liposomes, DOX, tumor, $\mathrm{pH}$ (low) insertion peptide

\section{Introduction}

Tumor microenvironment (TME), supporting the survival and development of cancer cells, has the special physical and chemical characteristic, such as low concentration of oxygen and low $\mathrm{pH}$ value, which not only play a key role in tumor progression and metastasis but also has an obvious impact on the therapeutic efficacy of tumors. ${ }^{1-4}$ In the acidic microenvironment of tumors, weakly alkaline drug molecules are easily protonated, preventing them from entering tumor cells 
and thus causing drug resistance. Therefore, investigating the regulatory effect of acidic TME on chemotherapy will help improving the resistance of chemotherapeutic drugs, thereby increasing the response rate and treatment efficacy of chemotherapy. ${ }^{5-9}$

In general, the extracellular $\mathrm{pH}$ in most tumor microenvironment is 6.5 to 6.8 , and that of the endosome/lysosome is 4.5 to 6.5 , both lower than the $\mathrm{pH}$ of normal tissues and blood (7.2 to 7.4). ${ }^{10}$ Taking advantage of this characteristic of tumors, researchers have developed various acidic pH-responsive nanocarriers, such as $\mathrm{pH}-$ responsive hydrogels, micelles, liposomes, and multiple sensitive materials. ${ }^{3,11}$ Among different $\mathrm{pH}$-responsive nanocarriers, $\mathrm{pH}$-responsive liposomes have been most investigated owing to their excellent biocompatibility and versatile modifiability. ${ }^{12}$ The $\mathrm{pH}$-responsive liposomes have been widely used to replace conventional liposome to improve the delivery efficiency of chemotherapeutic drugs, toxins, and siRNA. ${ }^{11,13}$ These $\mathrm{pH}$-responsive liposomes were mainly focused on the controlled release of drugs under acidic conditions. ${ }^{14}$ The most commonly used acid-sensitive strategy is using 1,2-dioleoyl-sn-glycerol3-phosphoethanolamine (DOPE) and weakly amphiphilic acid, cholesterol hemisuccinate (CHEMS) as the composition of the liposomes. ${ }^{15}$ The results showed that under the acid condition of lysosome, $\mathrm{pH}$-responsive liposomes transformed into the hexagonal crystal phase, which accelerated the release of drugs. ${ }^{16-19}$ However, many improvements are still needed to enhance the delivery efficiency of pH-responsive liposomes, such as tumor-targeting, stability, drug encapsulation efficiency. Nanoparticles that rely on the passive targeting of the EPR effect are likely to be highly enriched in the liver and cause greater toxicity, which may lead to clinical application failure. ${ }^{20,21}$ Actively targeted and stealth nanoparticles can reduce non-specific uptake in the liver and improve the efficiency of drug delivery to tumors. Stealth nanoparticles can be achieved simply by adding PEG components. ${ }^{22,23}$ Targeting capabilities can also be achieved by introducing targeting molecules into nanomaterials. Targeting molecules such as aptamers, ${ }^{24}$ antibodies, peptides, ${ }^{25}$ and ligands ${ }^{26}$ have been modified to $\mathrm{pH}$-sensitive liposomes to improve its tumor targeting. However, due to the heterogeneous of human tumor, ${ }^{27,28}$ these methods have some limitations.

Previously, a family of $\mathrm{pH}$ (low) insertion peptide (pHLIP) have been developed. The structure of pHLIP is random under neutral or alkaline condition, but in a slightly acidic microenvironment, it forms an alpha helix to insert into the cell membrane, ${ }^{29-32}$ thereby giving pHLIP the ability to target acidic TME. ${ }^{29-32}$ The in vitro cell experiments showed that pHLIP-modified dual $\mathrm{pH}$ responsive liposomes significantly improved the payload delivery and release efficiency compared with the original mono pH-responsive liposomes. ${ }^{33,34}$ Therefore, the pHLIP-mediated dual pH-responsive liposomes might have great potential to improve the in vivo tumor-targeted delivery efficiency of drugs. However, the in vivo therapeutic efficacy of pHLIP-modified dual $\mathrm{pH}$-responsive liposomes has not been validated.

In this study, a novel DVar7 ( ${ }^{\mathrm{D} A C E E Q N O W A R Y L E W L F P T E T L L L E L) ~ p e p t i d e-b a s e d ~}$ dual pH-responsive DOX-encapsulated liposome (DOPEDVar7-lip@DOX) was designed and evaluated for in vivo therapeutic efficacy. Compared to original pHLIP, the truncated Var7 peptide showed higher tumor targeting, ${ }^{32}$ thus the nanocarriers modified with Var7 could lead to an enhanced tumor delivery efficiency. Besides, DVar7, as a D-type peptide, is more stable in vivo than the previously used L-pHLIP, which can further ensure the drug delivery efficiency of the cargo in tumors. In addition, unlike most dual acid-responsive nanomaterials that require complicated technology to achieve, DVar7 modified liposomes can be obtained by simply incubating DSPE-DVar7 with traditional DOX-liposome. The composition of doxorubicin-loaded dual $\mathrm{pH}$-sensitive liposomes and their action after intravenous administration are shown in Figure 1. In the end, the therapeutic efficacy of dual $\mathrm{pH}$ responsive liposome DOPE-DVar7-lip@DOX was evaluated in breast cancer mouse model, and the effect of $\mathrm{pH}$ adjustment by glucose injection on the anticancer efficacy of dual $\mathrm{pH}$ responsive liposomes was further assessed.

\section{Materials and Methods Materials}

1.2-Dioleoyl-sn-glycero-3-phosphoethanolamine (DOPE), 1.2-Dioleoyl-sn-glycero-3-phosphocholine (DOPC), and cholesterol and cholesteryl hemisuccinate (CHEMS) were purchased from A.V.T. (Shanghai, China). 1.2-Distearoyl-snglycero-3-phosphoethanolamine-N-[methoxy(polyethylene glycol)-2000] (DSPE-PEG ${ }_{2000}$ ) was purchased from NOF Corporation (Tokyo, Japan). DSPE-PEG 2000 -MAL was purchased from Xi'an ruixi Biological Technology (Xi'an, China). HEPES, EDTA $2 \mathrm{Na} \cdot 2 \mathrm{H}_{2} \mathrm{O}$ and doxycycline hyclate $(\mathrm{DOX} \cdot \mathrm{HCl})$ were supplied by Sigma-Aldrich (Shanghai, China). DVar7 ${ }^{\mathrm{D}}$ (ACEEQNOWARYLEWLFPTETLLLEL) 


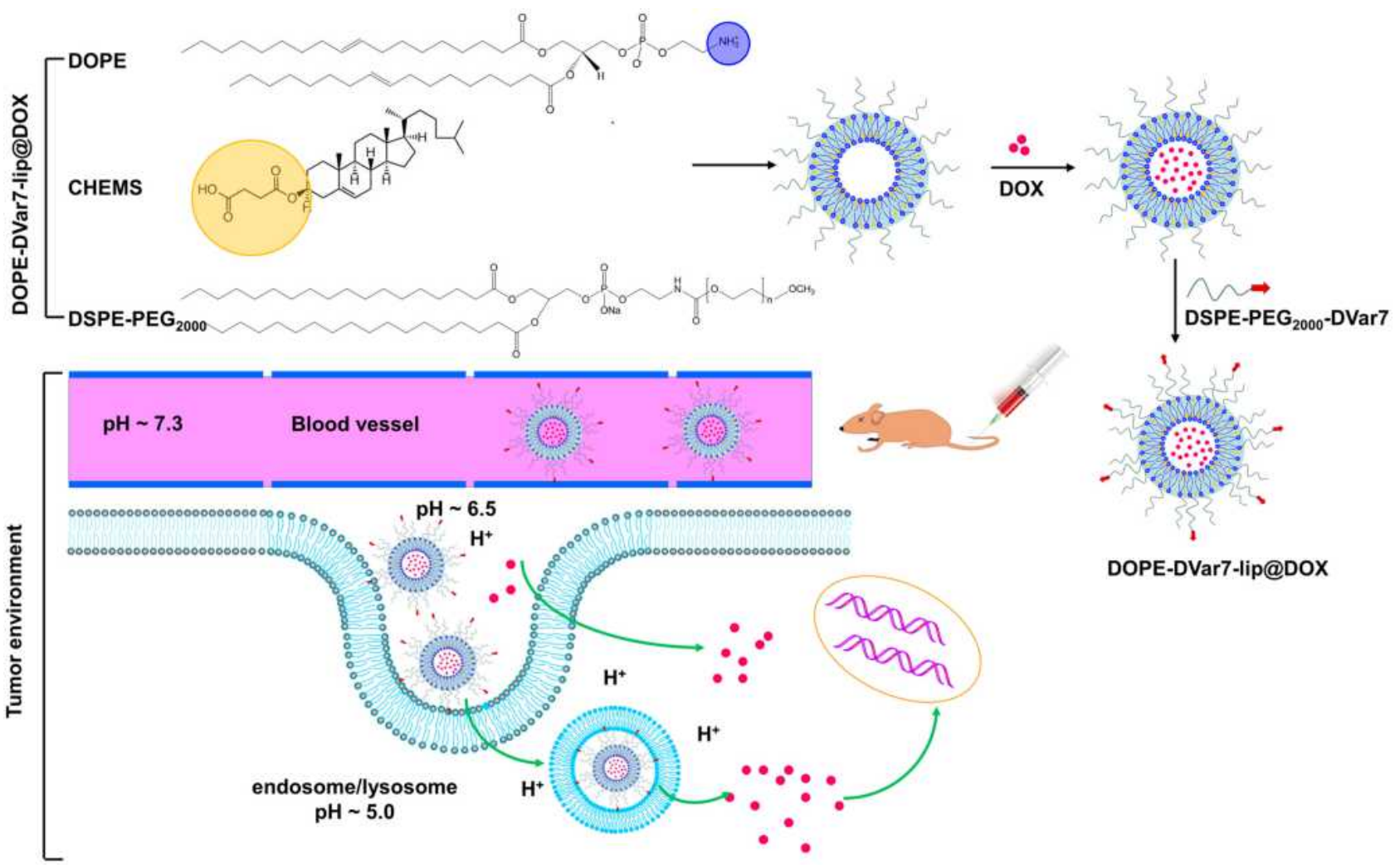

Figure I Preparation of DOPE-DVar7-lip@DOX and its anticancer mechanism. DOPE-DVar7-lip@DOX was prepared by coating doxorubicin with DOPE-liposomes and modifying DOPE-lip@DOX with DVar7. In the tumor acidic microenvironment, DVar7 folded and formed the alpha helix and inserted into the cell membrane, increasing the retention of liposomes in tumor and promoting the fusion of liposome with the cell membrane. Liposomes that were endocytosed into tumor cells quickly released doxorubicin upon the strongly acidic conditions of the lysosome. Therefore, doxorubicin could achieve a high concentration inside tumor cells during a short time, and then enter the nucleus to kill tumor cells.

was synthesized by GL Biochem (Shanghai, China). LysoTracker Red was purchased from Shanghai Yeasen Biotech (Shanghai, China). The other chemicals and reagents were analytical grade.

\section{Cell Cultures}

It has been reported that highly metastatic tumor cells, such as MDA-MB-231 and MDA-MB-435, have a lower pHe than non-metastatic MCF-7 tumors of the same size. ${ }^{35}$ Therefore, MDA-MB-435S cell was chose as the positive cell line. Hela cell line was selected as a control cell line to prove that the uptake of acid-sensitive nanoparticles at different $\mathrm{pH}$ in cell experiments in vitro is mainly related to $\mathrm{pH}$ changes, and has nothing to do with cell types. The MDA-MB-435S and HeLa cells were purchased from American Type Culture Collection (ATCC, Manassas, VA, USA) and maintained under standard conditions according to ATCC. Fetal bovine serum, Leibovitz's L15 medium, DMEM, trypsin, and penicillin-streptomycin solution were obtained from M\&C Gene Technology (Beijing, China). MDA-MB-435S cells were cultured in
Leibovitz's L15 medium with 10\% fetal bovine serum and $1 \%$ penicillin streptomycin combination and kept at $37{ }^{\circ} \mathrm{C}$ without $\mathrm{CO}_{2}$. HeLa cells were cultured in DMEM with $10 \%$ fetal bovine serum and $1 \%$ penicillin streptomycin combination and kept at $37{ }^{\circ} \mathrm{C}$ under $5 \% \mathrm{CO}_{2}$. The cells were harvested with trypsin, and the cell suspension was used for experiments.

\section{Animal Model}

All animal experiments were performed in accordance with the guidelines of Peking University Health Science Center Animal Care and Use Committee. The subcutaneous MDA-MB-435S mouse model was established by subcutaneous injection of $5 \times 10^{6}$ cells into the right front flank of female nude mice $(\sim 15 \mathrm{~g}, \mathrm{BABL} / \mathrm{c})$. The mice were used for imaging studies when the tumor volume reached approximately $200 \sim 300 \mathrm{~mm}^{3}$ (3-4 weeks after inoculation). The mice were used for the therapeutic experiment when the tumor volume reached approximately $50-100 \mathrm{~mm}^{3}(\sim 2$ weeks after inoculation). All animal experimental protocols were approved 
by Peking University Health Science Center Animal Care and Use Committee.

\section{Synthesis of DSPE-PEG 2000 -DVar7}

DSPE-PEG $_{2000}$-DVar7 was synthesized by the covalent conjugation of DSPE-PEG 2000 -maleimide with the single cysteine residue at the N-terminus of DVar7. Briefly, DSPE-PEG $_{2000}$-MAL $3.53 \mathrm{mg}(\sim 1.2 \mu \mathrm{mol})$ was dissolved in chloroform and evaporated to form a thin film in a round flask. The film was hydrated with HBS solution (pH 7.0) for $20 \mathrm{~min}$ and sonicated at $37{ }^{\circ} \mathrm{C}$ for $5 \mathrm{~min}$. After DVar7 $3.065 \mathrm{mg}(\sim 1 \mu \mathrm{mol})$ was added to the mixture and oscillated until completely dissolved, the mixture was separated by the reversed-phase high-performance liquid chromatography (HPLC) system. A Sepax Bio-C4 column $(10 \times 250 \mathrm{~mm})$ was used for DSPE-PEG 2000 -DVar7 purification with a flow rate of $3 \mathrm{~mL} / \mathrm{min}$. For analytical HPLC, a Sepax Bio-C4 $(4.6 \times 250 \mathrm{~mm})$ was used with a flow rate of $1 \mathrm{~mL} / \mathrm{min}$. The monitor wavelength was 254 $\mathrm{nm}$, and the injection volume was $20 \mu \mathrm{L}$. The mobile phase was changed from $60 \%$ solvent A $(0.1 \%$ trifluoroacetic acid [TFA] in water) and $40 \%$ solvent B $(0.1 \%$ TFA in acetonitrile $[\mathrm{ACN}])(0-5 \mathrm{~min})$ to $20 \%$ solvent $\mathrm{A}$ and $80 \%$ solvent $\mathrm{B}$ at $15 \mathrm{~min}$, followed by a gradient mobile phase from $0 \%$ solvent $\mathrm{A}$ and $100 \%$ solvent $\mathrm{B}$ at $35 \mathrm{~min}$ to $60 \%$ solvent $A$ and $40 \%$ solvent $B$ at $40 \mathrm{~min}$. The existence of the product was ensured by SELDI-TOF massspectrometry analysis.

\section{Preparation and Characterization of Liposomes}

Both pH-responsive PEGylated liposomes (pSPL) and non-pH-responsive liposomes (nSPL) were prepared using a thin-film hydration method. Firstly, we prepared fluorescent liposomes DOPE-DVar7-lip@Cy5.5. The detailed composition of fluorescent liposomes used in the study is given in Table 1. A chloroform solution of the desired lipid mixture $(\sim 20 \mu \mathrm{mol})$ without DSPE-PEG $2000^{-}$ DVar7 was vortexed and evaporated to form a thin film in a round flask equipped with a rotary evaporator at $37{ }^{\circ} \mathrm{C}$ under aspirator vacuum, continuing to evaporate for $5 \mathrm{~min}$ to remove residual organic solvent. Then, the film was hydrated with $1 \mathrm{~mL}$ of HBS solution (10 mM HEPES, $150 \mathrm{mM} \mathrm{NaCl}, \mathrm{pH} 8.0$ ) at $37{ }^{\circ} \mathrm{C}$ for $20 \mathrm{~min}$ to form multicellular vesicles (MLVs). MLVs were subjected to a miniature ultrasonic probe for $10 \mathrm{~min}$ (ultrasound 1 $\mathrm{s}$ and pause $1 \mathrm{~s}$ ) to form small, unilamellar vesicles. The
Table I Formulation of Cy5.5-Loaded Liposomes

\begin{tabular}{|l|l|l|l|}
\hline & $\begin{array}{l}\text { DOPC- } \\
\text { lip@Cy5.5 }\end{array}$ & $\begin{array}{l}\text { DOPE- } \\
\text { lip@Cy5.5 }\end{array}$ & $\begin{array}{l}\text { DOPE-DVar7- } \\
\text { lip@Cy5.5 }\end{array}$ \\
\hline Chol & $40 \%$ & $0 \%$ & $0 \%$ \\
\hline DOPC & $54 \%$ & $0 \%$ & $0 \%$ \\
\hline CHEMS & $0 \%$ & $40 \%$ & $40 \%$ \\
\hline DOPE & $0 \%$ & $54 \%$ & $54 \%$ \\
\hline DSPE-PEG 2000 & $6 \%$ & $6 \%$ & $4 \%$ \\
\hline $\begin{array}{l}\text { DSPE-PEG } \\
\text { DVar7 }\end{array}$ & $0 \%$ & $0 \%$ & $2 \%$ \\
\hline Cy5.5 & $1 \%$ & $1 \%$ & $1 \%$ \\
\hline
\end{tabular}

DOPE-DVar7-lip@Cy5.5 was prepared by mixing 2\% mol percentage of DSPE-PEG 2000 -DVar7 with fluorescent liposomes DOPE-lip@Cy5.5 at $55^{\circ} \mathrm{C}$ for 1 h. Liposomes were sterilized by filtering through a $0.2 \mu \mathrm{m}$ Millipore filter into a sterile vial and stored at $4{ }^{\circ} \mathrm{C}$ for in vitro and in vivo experiments.

DOX-loaded pSPL and nSPL were prepared by the thin-film hydration method followed by the transmembrane $\mathrm{pH}$ gradient method. The detailed composition of DOX-loaded liposomes used in the study is shown in Table 2. The blank liposome suspensions were prepared by the same procedure as fluorescent liposomes. While the film of DOPC-lip@DOX was hydrated with $1.5 \mathrm{~mL}$ $0.25 \mathrm{~mol} / \mathrm{L}\left(\mathrm{NH}_{4}\right)_{2} \mathrm{SO}_{4}(\mathrm{pH} 5.23)$, the films of DOPElip@DOX and DOPE-DVar7-lip@DOX were hydrated with $1.5 \mathrm{~mL} \quad 0.25 \mathrm{~mol} / \mathrm{L}\left(\mathrm{NH}_{4}\right)_{2} \mathrm{SO}_{4}(\mathrm{pH} \quad 7.0)$. The blank liposome suspension of DOPC-lip@DOX was eluted using Sephadex G-25 (PD-10 desalting column) pre-equilibrated with HBS solution (10 mM HEPES, 150

Table 2 Formulation of DOX-Loaded Liposomes

\begin{tabular}{|l|l|l|l|}
\hline & $\begin{array}{l}\text { DOPC- } \\
\text { lip@DOX }\end{array}$ & $\begin{array}{l}\text { DOPE- } \\
\text { lip@DOX }\end{array}$ & $\begin{array}{l}\text { DOPE-DVar7- } \\
\text { lip@DOX }\end{array}$ \\
\hline Chol & $40 \%$ & $0 \%$ & $0 \%$ \\
\hline DOPC & $54 \%$ & $0 \%$ & $0 \%$ \\
\hline CHEMS & $0 \%$ & $40 \%$ & $40 \%$ \\
\hline DOPE & $0 \%$ & $54 \%$ & $54 \%$ \\
\hline DSPE-PEG 2000 & $6 \%$ & $6 \%$ & $4 \%$ \\
\hline $\begin{array}{l}\text { DSPE-PEG } \\
\text { DVar7 }\end{array}$ & $0 \%$ & $0 \%$ & $2 \%$ \\
\hline
\end{tabular}


$\mathrm{mM} \mathrm{NaCl}, \mathrm{pH} 7.8$ ) to form a $\mathrm{pH}$ gradient. DOX at $\mathrm{pH} 7.8$ with a ratio of 1:10 (w/w, DOX/lipids) was introduced into the liposome suspension at $37{ }^{\circ} \mathrm{C}$ for $1 \mathrm{~h}$, and an excess of free DOX was removed by washing with HBS solution. The blank liposome suspensions of DOPElip@DOX and DOPE-DVar7-lip@DOX were prepared by the same procedure as the $\mathrm{PB}$ solution $(\mathrm{pH} 9.0)$ to replace the HBS solution. The DOPE-DVar7-lip@DOX was prepared by mixing 2\% mol percentage of DSPE$\mathrm{PEG}_{2000}$-DVar7 with DOX-loaded liposomes DOPElip@DOX at $55{ }^{\circ} \mathrm{C}$ for $1 \mathrm{~h}$. Liposomes were sterilized by filtering through a $0.2 \mu \mathrm{m}$ Millipore filter into a sterile vial and stored at $4{ }^{\circ} \mathrm{C}$ for in vitro and in vivo experiments.

\section{Characterization of Liposomes}

The size, PDI, and zeta potential of the samples were measured using a Malvern Zetasizer (Brookhaven Instruments, Holtsville, NY) at $25^{\circ} \mathrm{C}$ based on the principles of dynamic light scattering (DLS). Samples were typically $200 \mathrm{nmol}$ liposomes in $1 \mathrm{~mL}$ of HBS solution (10 mM HEPES, $150 \mathrm{mM} \mathrm{NaCl}$, pH 8.0).

The morphology of liposomes was observed using a transmission electron microscope (TecnaiG220, FEI, Hillsboro, OR, USA). The liposomal solution was dropped onto a carbon-coated copper grid followed by drying in air, and the sample was then subjected to observation.

\section{Encapsulation Efficiency (EE) and Loading Efficiency (LE)}

To determine encapsulation efficiency (\%EE) and loading efficiency (\%LE), firstly, the standard curve of DOX was drawn. The DOX solution was diluted to eight different concentrations with $5,10,15,20,25,30,40$, and $50 \mu \mathrm{g} /$ $\mathrm{mL}$. Using the ultrapure water as blank control. The excitation wavelength of microplate reader was set at $480 \mathrm{~nm}$, and the absorbance values of DOX solutions with different concentrations were measured. The standard curve of absorbance and concentration was drawn. The standard equation of DOX absorbance(y) and concentration( $\mathrm{x}$ ) was $\mathrm{y}=0.0222 \mathrm{x}$, and the correlation coefficient $\mathrm{R}^{2}$ was 0.9998 , indicating that there was a good linear relationship between DOX concentration and absorbance value in the range of $0-50 \mu \mathrm{g} / \mathrm{mL}$.

The procedure in detail as follows: After doxorubicin encapsulation was completed, take two copies of $200 \mu \mathrm{L}$ DOX loaded liposome solution, one of which was adjusted to $500 \mu \mathrm{L}$ with buffer, then added $1 \mathrm{~mL}$ acidic isopropanol for demulsification, and react on the oscillator for $10 \mathrm{~min}$. The blank control was $500 \mu \mathrm{L}$ HBS buffer, added with $1 \mathrm{~mL}$ acidic isopropanol. Then, took $100 \mu \mathrm{L}$ samples each and added them to the 96-well plate. The wavelength of the microplate reader SH-9000 (Corona Electric, Ibaraki, Japan) was set at $480 \mathrm{~nm}$. Measure the absorbance and calculate the doxorubicin content. Passing the other copy through P-10 column, eluting with HBS buffer solution with $\mathrm{pH} 7.8$, collecting the liposome part, and using buffer solution to increase the volume to $500 \mu \mathrm{L}$, after demulsification, measuring the absorbance value with microplate reader, and calculating the DOX content, which represents the DOX content loaded by liposomes.

EE was calculated as the amount of drug loaded in the liposomes divided by the initial amount of the drug. Encapsulation efficiency $(\% \mathrm{EE})=$ Amount of drug loaded in liposomes/Amount of drug added $\times 100 \%$. LE was calculated as the molar ratio of the drug loaded into liposomes to the total of lipids. Loading efficiency $(\% \mathrm{LE})=$ Amount of drug in liposomes/Amount of liposomes $\times$ $100 \%$. The encapsulation efficiency (\%EE) of DOPClip@DOX, DOPE-lip@DOX, DOPE-DVar7-lip@DOX were $98 \%, 90 \%$, and 93\%, respectively. The loading efficiency (\%LE) of DOPC-lip@DOX, DOPE-lip@DOX, DOPE-DVar7-lip@DOX was 9.8\%,9.0\%, and 9.3\%, respectively.

\section{In vitro Stability and Acid Sensitivity}

The physicochemical stability of liposomes was investigated over 30 days. Liposomes were stored at $4{ }^{\circ} \mathrm{C}$ and room temperature. Particle size and distribution of liposomes were measured on day 0 , day 7 and day 30. The leakage rate of DOX liposomes was monitored with an enzyme standard instrument after separation and purification by a PD-10 column. The acid sensitivity of liposomes was assessed by measuring particle size changes after the liposomes were incubated with different $\mathrm{pH}$ solutions for an hour.

\section{In vitro Drug Release of DOX Liposomes}

The DOX release rates from liposomes with different $\mathrm{pH}$ values were investigated using a dialysis method. Briefly, $1 \mathrm{~mL}$ of DOX-loaded liposomes was transferred to a dialysis bag (MWCO 35000 Da, Beijing Solarbio Science \& Technology Co., Ltd. Beijing, China) and then dialyzed against $40 \mathrm{~mL}$ of release medium with different $\mathrm{pH}$ in a tube and placed in a shaking incubator at $37{ }^{\circ} \mathrm{C}$. 
One milliliter of media was removed at 1, 2, 4, 8, 24, $48 \mathrm{~h}$, and an equivalent volume of fresh media was added at the same time. The amount of released DOX was determined using the multiscan spectrum with an excitation wavelength of $480 \mathrm{~nm}$. The last time point result was used to calculate the DOX release rate.

\section{Cellular Uptake}

The in vitro cellular uptake of Cy5.5 fluorescent liposomes was evaluated in MDA-MB-435S cancer cells and HeLa cancer cells. Briefly, the cells were seeded at a density of $2 \times 10^{4}$ per well in glass bottom cell culture dishes and incubated for $24 \mathrm{~h}$ at $37{ }^{\circ} \mathrm{C}$. Then, $100 \mu \mathrm{L}$ fluorescent liposomes (at a final Cy5.5 concentration of $20 \mu \mathrm{M}$ ) with different $\mathrm{pH}$ values (6.0 and 7.4) was added and incubated for $1 \mathrm{~h}$. The cells were washed twice with ice-cold PBS and further analyzed by a FACSCalibur system. CLSM was used to study the cellular uptake and intracellular release behaviors of DOX-loaded liposomes in MDAMB-435S. Briefly, the cells were seeded at a density of $2 \times 10^{4}$ per well in glass bottom cell culture dishes and incubated for $24 \mathrm{~h}$ at $37^{\circ} \mathrm{C}$. Then, $100 \mu \mathrm{L}$ of free DOX or DOX-loaded liposomes with different $\mathrm{pH}$ values was added and incubated for $1 \mathrm{~h}$. The cells were washed twice with ice-cold PBS. The cell nuclei were stained with 100 $\mu \mathrm{L}$ of Hoechst $33342(1 \mu \mathrm{g} / \mathrm{mL})$, and lysosomes were stained with LysoTracker Red for $20 \mathrm{~min}$. After washing with PBS three times, the fluorescence images were captured by a TCS-NT confocal microscope (Wetzler, Heidelberg, Germany). The fluorescence intensity of DOX in cells was analyzed by using ImageJ software.

\section{In vitro Cytotoxicity}

First, we used flow cytometry to determine the change in doxorubicin liposome uptake with incubation time and determined the optimal drug action time of the MTT experiment was $4 \mathrm{~h}$. Briefly, co-incubated doxorubicin liposomes (the final concentration was $20 \mu \mathrm{g} / \mathrm{mL}$ ) and $1 \mathrm{~mL}$ MDA-MB-435S tumor cells $\left(2 \times 10^{6} / \mathrm{mL}\right)$ for 1,2 , 4 , or $8 \mathrm{~h}$, and then the cells were washed with PBS three times. Flow cytometry was performed to determine the changes in doxorubicin fluorescence intensity in the cell with time. The cytotoxicity of blank lipids and DOXloaded liposomes in MDA-MB-435S cells was evaluated by MTT assay. The cells were plated in a 96-well plate $\left(1 \times 10^{4}\right.$ cells $/$ well $)$ and incubated at $37{ }^{\circ} \mathrm{C}$ in an atmosphere containing $5 \% \mathrm{CO}_{2}$ overnight. Then, the cell culture media was replaced with fresh media with different $\mathrm{pH}$ values containing blank lipids, DOX.HCl, or DOX-loaded liposomes with different concentrations and incubated for 4 $\mathrm{h}$. Then, the medium was replaced with fresh medium of the corresponding $\mathrm{pH}$ and cultured for $48 \mathrm{~h}$. The nontreated cells were used as negative controls. After $48 \mathrm{~h}$, the medium was replaced by a mixture of $100 \mu \mathrm{L}$ of fresh medium and $20 \mu \mathrm{L}$ of MTT. After incubating for $1 \mathrm{~h}$, the absorbance was determined at $490 \mathrm{~nm}$ by a microplate reader. The cell viability was estimated, and $\mathrm{IC}_{50}$ values were calculated using GraphPad Prism software (GraphPad Software, Inc., La Jolla, CA, USA).

\section{In vivo Tumor Targeting}

MDA-MB-435S cells $\left(5 \times 10^{6}\right.$ per mouse $)$ were subcutaneously injected into the right flank of the mice. When the tumor size reached $200-300 \mathrm{~mm}^{3}$, tumor-bearing mice were intravenously injected with $100 \mu \mathrm{L}$ liposomes (DOPC-lip@Cy5.5, DOPE-lip@Cy5.5, DOPE-DVar7lip@Cy5.5, n =3, the amount of Cy5.5 was $10 \mathrm{nmol}$ ). The last group received a high concentration glucose injection 45 min before the DOPE-DVar7-lip@Cy5.5 liposomes injection. Fluorescence images were acquired by an IVIS Spectrum imaging system at 4, 24, 48, and $72 \mathrm{~h}$ postinjection. The excitation filter was $675 \mathrm{~nm}$, and the emission filter was $723 \mathrm{~nm}$. The fluorescence signals of the tumor and the contralateral thigh were recorded using the IVIS Spectrum imaging system for quantification. The results were statistically analyzed using GraphPad Prism software (GraphPad Software, Inc., La Jolla, CA, USA).

\section{In vivo Antitumor Efficacy}

For the tumor suppression study, MDA-MB-435S cells $\left(5 \times 10^{6}\right.$ per mouse $)$ were subcutaneously injected into the right flank of the mice. When the tumor size reached $50-100 \mathrm{~mm}^{3}$, these mice were divided into seven groups $\left(\mathrm{n}=6\right.$, mean tumor size was $\left.63.5 \mathrm{~mm}^{3}\right)$. After the preparation of liposomes, we have removed the free DOX by purification with PD-10 column and determined the encapsulation efficiency (EE), loading efficiency (LE), and final concentration of DOX in liposomes. Saline, free DOX, DOPC-lip@DOX, DOPE-lip@DOX, DOPE-DVar7lip@DOX, DOPC-lip@DOX combined with glucose injection, or DOPE-DVar7-lip@DOX combined with glucose injection was injected into the mice via the tail vein at a dose of $5 \mathrm{mg} / \mathrm{kg}$ of DOX equivalent. Before injection, DOX-loaded liposomes were diluted with PBS to the appropriate concentration to achieve an administration volume of about $100 \mu \mathrm{L}$. The injections were given 
every four days for a total of five times. The tumor sizes were measured by a calliper every other day after treatment. Tumor volume (V) was calculated by the following equation: $\mathrm{V}=\mathrm{AB}^{2} \times 0.5$, where $\mathrm{A}$ was the longer and $\mathrm{B}$ was the shorter diameter $(\mathrm{mm})$. The relative tumor volumes were normalized to their initial sizes. Meanwhile, body weight was calculated during the treatment period. At the end of treatment, the mice were sacrificed to collect tumors and heart, liver, spleen, lung, and kidney tissues for further analyses. The tumor weight was measured by a balance and analyzed statistically. Finally, the tumor and other tissues were used for the H\&E staining.

For histological analysis, the tumors and other tissues were cut into $5 \mu \mathrm{m}$ thick sections and stained with hematoxylin and eosin (H\&E), and the sections were observed under an optical microscope.

\section{Statistical Analysis}

Data are presented as the mean \pm SEM. Differences between the groups were assessed by one-way ANOVA, and a $\mathrm{P}$ value less than 0.05 was considered significant.

\section{Results and Discussion Preparation and Characterization of Liposomes}

The preparation of the dual $\mathrm{pH}$-responsive drug-loaded lipid system can be divided into three steps: (i) preparation of DOPE liposomes; (ii) preparation of DOX-loaded DOPE liposomes; and (iii) modification DOX-loaded DOPE liposome with targeting molecule DSPE-PEG ${ }_{2000}$ DVar7. The targeting molecule DSPE-PEG $2000^{-D V a r 7}$ was synthesized by coupling DSPE-PEG $2000-\mathrm{MAL}$ with DVar7, and the product was validated by mass spectrometry (Supplementary Figure S1). Polyethylene glycol (PEG) motif at $6 \%$ of molar ratio was introduced into liposomes through the insertion of DSPE-PEG 2000 and DSPE-PEG $_{2000}$-DVar7, which could not only keep liposomes stable and reduce the leakage of drugs during the circulation in blood but also reduce the nonspecific interaction between liposomes and serum proteins, thus preventing the clearance of liposomes in the reticular endothelial system (RES). ${ }^{36}$ Blank DOPE liposomes were prepared with DOPE, CHEMS, and DSPE-PEG 2000 by the thin-film hydration method. Doxorubicin liposomes were prepared by $\mathrm{pH}$ gradient loading method.

Dynamic light scattering (DLS) analysis indicated that the hydrodynamic diameter of the liposomes was approximately $130 \mathrm{~nm}$ with a polydispersity index (PDI) of $<0.2$ (Figure 2A). The results of transmission electron microscopy indicated that the particle size of liposomes was approximately $130 \mathrm{~nm}$ (Figure 2B). Detailed nanoparticle characterizations of Cy5.5-loaded liposomes and DOX-loaded liposomes were provided in Supplementary Figure S2. The particle size of the Cy5.5-loaded liposomes remained stable for 30 days (Supplementary Figure S3). Ultraviolet (UV) absorption spectroscopy results showed that the maximum UV absorption wavelength of free DOX was $480 \mathrm{~nm}$, and the maximum absorption wavelength of doxorubicin liposomes was $497 \mathrm{~nm}$ with a reduced redshift (Figure 2C), indicating the successful encapsulation of DOX. The encapsulation rate of DOX in the three liposomes was $98 \%, 90 \%$, and 93\%, respectively. The DOXloaded liposomes had no significant change in particle size for 30 days at $4^{\circ} \mathrm{C}$ and room temperature (Supplementary Figure S4), the PDIs were remain $<0.2$, and the drug leakage rates were less than $3 \%$, indicating good stability.

\section{In vitro Acid-Triggered Drug Release from Liposomes}

In vitro acid-sensitivity was determined by measuring the particle size change under different $\mathrm{pH}$ conditions with DLS (Figure 2D). The particle size of DOPC-lip@DOX liposomes was barely changed along with the decrease of $\mathrm{pH}$ and remained at approximately $135 \mathrm{~nm}$. With the decrease of $\mathrm{pH}$, the particle size of DOPE-lip@DOX and DOPE-DVar7-lip@DOX liposomes increased from 130 $\mathrm{nm}$ to $150 \mathrm{~nm}$, which indicating that liposomes were acid-sensitive in vitro.

Afterward, to confirm that $\mathrm{pH}$-responsive controlled drug release of liposomes, we measured the drug release of doxorubicin liposomes under different $\mathrm{pH}$ conditions by dialysis and obtained a drug release curve by measuring the concentration of DOX in the dialysis medium at different time points. The results were standardized with the release curve at $\mathrm{pH} \mathrm{7.4,} \mathrm{and} \mathrm{the} \mathrm{drug} \mathrm{release} \mathrm{rates} \mathrm{of} \mathrm{the}$ three drug-carrying liposomes under different $\mathrm{pH}$ conditions were obtained (Figure 2E). With the decrease of $\mathrm{pH}$, DOPC-lip@DOX at pH 5.3 released twice as much drug as at pH 7.4. The drug release of DOPE-lip@DOX increased significantly at $\mathrm{pH} 5.3$, which was three times

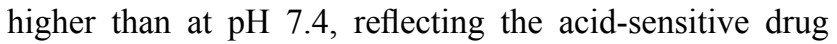
release characteristics of DOPE lipid structure. Furthermore, DOPE-DVar7-lip@DOX at pH 5.3 released nearly five times more drugs than at $\mathrm{pH}$ 7.4. This should 


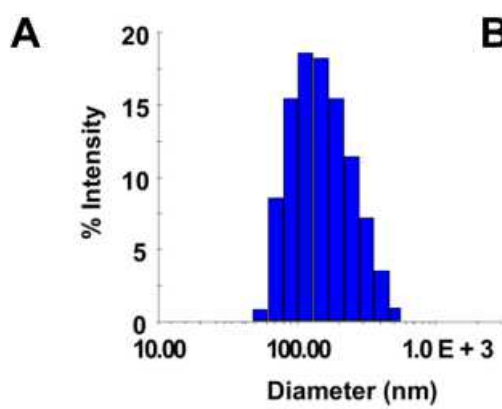

C

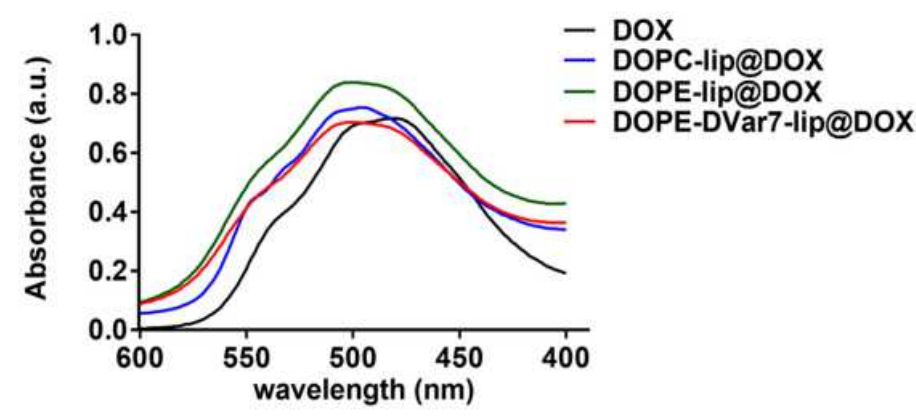

B

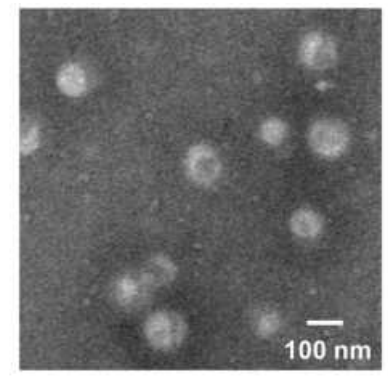

$\mathbf{E}$

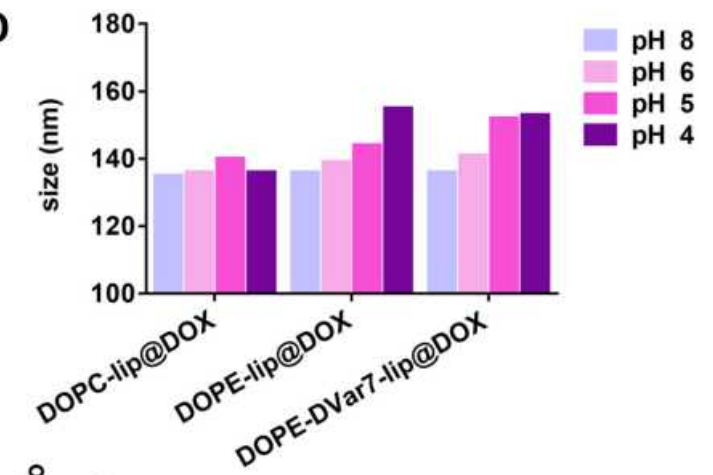

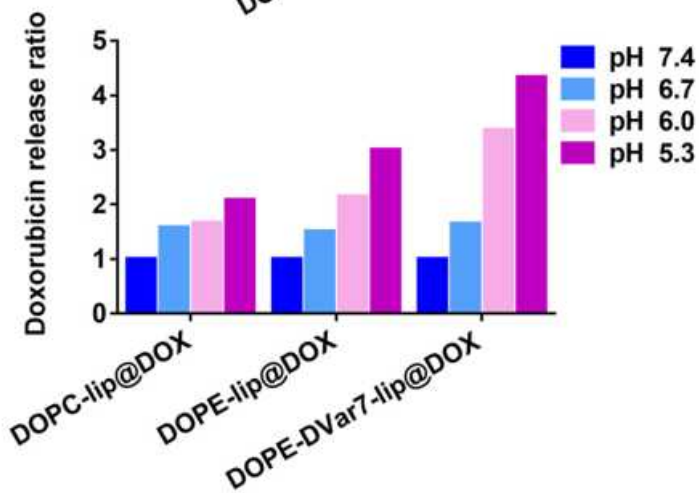

Figure 2 Characterization of liposomes. (A) The size distribution of liposomes. (B) TEM micrograph of liposomes. (C) The ultraviolet absorption spectrum of DOX and DOX-loaded liposomes. (D) Size of liposomes in solutions with different $\mathrm{pH}$ values. (E) Doxorubicin release ratio of liposomes in solutions with different $\mathrm{pH}$ values.

be attributed to the structural change of DVar7, which was inserted into the phospholipid bilayer under acidic conditions, bringing the liposomes and cell membranes close to each other, thereby increasing the interaction, leading to the destruction of liposome structure, and increasing the drug release from the liposomes. ${ }^{34}$ These results confirmed that DOPE-liposomes were acid-sensitive and their increased release of DOX was triggered by an acidic environment. In addition, the presence of DVar7 further accelerated the release of DOX in acidic environment.

\section{In vitro Cell Uptake}

Since the cell uptake of pSPL and nSPL can be visually compared under confocal microscopy, we evaluated the cellular uptake behavior of fluorescent liposomes in HeLa and MDA-MB-435S cells (Supplementary Figure S5) and measured the fluorescence intensity of the cells to reflect the uptake of fluorescent liposomes. The fluorescence intensity was quantitatively analyzed with Image J software. As shown in Figure $3 \mathrm{~A}$ and $\mathrm{B}$, in the two cell lines, there was no significant difference in uptake between these three fluorescent liposomes at $\mathrm{pH}$ 7.4. However, at pH 6.0, compared with DOPClip@Cy5.5, the acid-sensitive DOPE-lip@Cy5.5 liposomes showed significantly increased uptake in tumor cells (MDA-MB-435S: $6.97 \pm 0.01$ vs $5.82 \pm 0.07, \mathrm{n}=3$, $* * * * \mathrm{p}<0.0001$; HeLa: $7.40 \pm 0.02$ vs $5.82 \pm 0.07, \mathrm{n}=$ 3 , ****p $<0.0001)$. Compared with DOPE-lip@Cy5.5, the dual pH-responsive liposomes (DOPE-DVar7lip@Cy5.5) showed further increased uptake in tumor cells (MDA-MB-435S: $7.55 \pm 0.04$ vs $6.97 \pm 0.01, \mathrm{n}=$ 3 , ***p<0.001; HeLa: $7.75 \pm 0.03$ vs $7.40 \pm 0.02$, $* * * \mathrm{p}<0.001)$. These results showed that dual acid-sensitive fluorescent liposomes had a notable advantage on increasing cell uptake at $\mathrm{pH}$ 6.0, and this was independent of cell types. For both two cell lines, tumor cell uptake of pSPL increased significantly under at $\mathrm{pH} 6.0$ compared to $\mathrm{pH} 7.4$.

MDA-MB-435S cells were used to evaluate the cell uptake of DOX-loaded liposomes in different $\mathrm{pH}$ conditions. As shown in Figure $3 \mathrm{C}$ and $\mathrm{D}$, free DOX and DOPC-lip@DOX liposomes had no significant differences in uptake under different $\mathrm{pH}$ conditions. However, at $\mathrm{pH} 6.0$, the cellular uptake of DOPElip@DOX and DOPE-DVar7-lip@DOX was much higher than that at pH 7.4 (DOPE-lip@DOX: 3591.00 \pm 38.92 vs $3157.00 \pm 22.18, \mathrm{n}=3, * * * \mathrm{p}<0.001$; DOPEDVar7-lip@DOX: $4671.00 \pm 144.10$ vs $3748.00 \pm$ $109.80, \mathrm{n}=3, * * \mathrm{p}<0.01)$. 
A

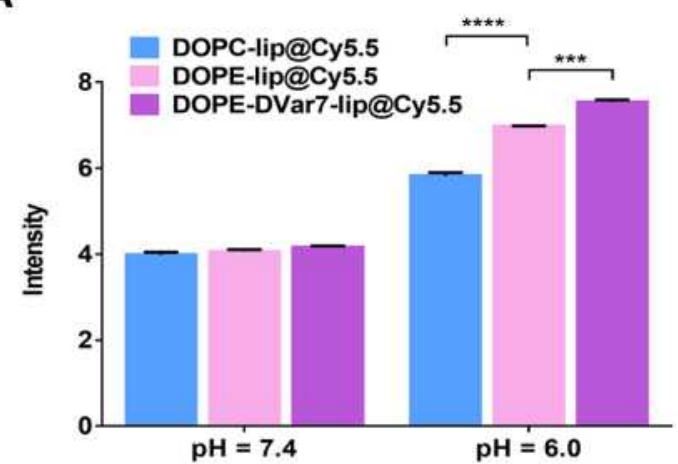

B

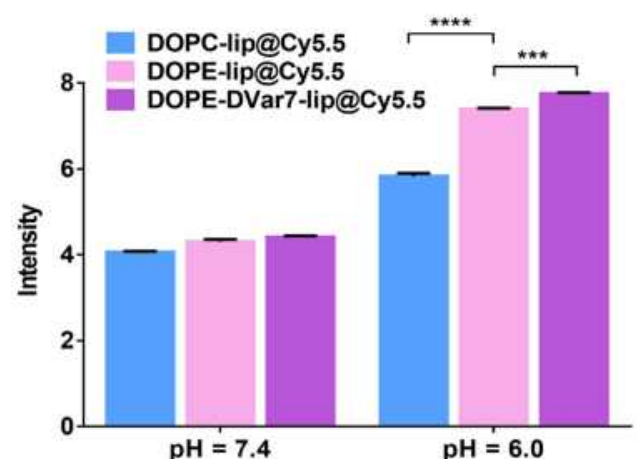

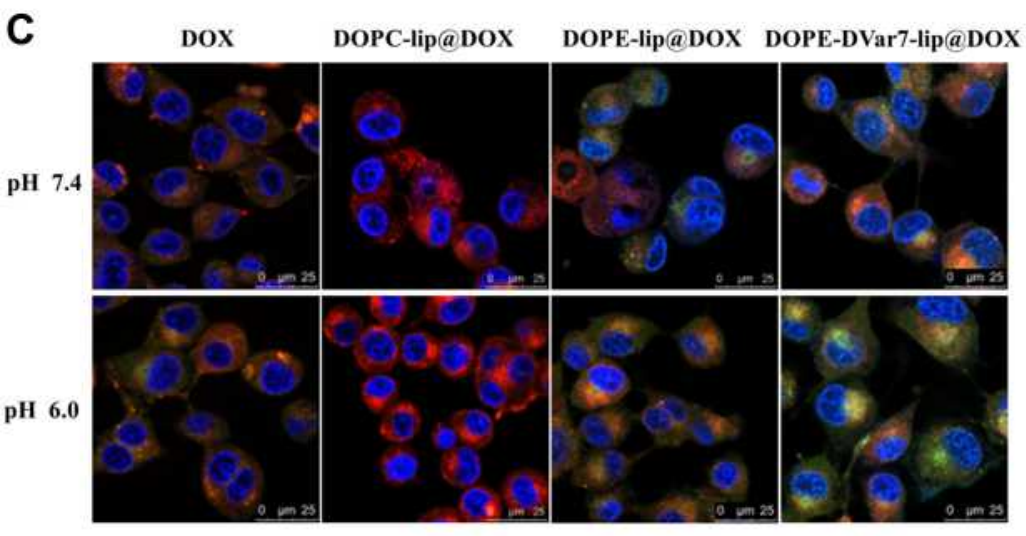

E

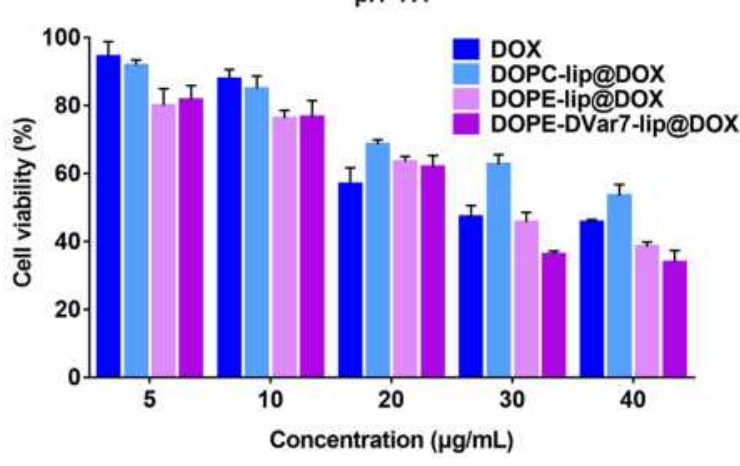

D

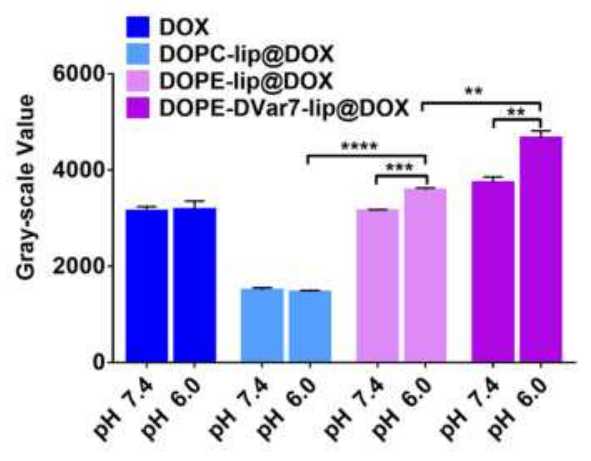

$\mathbf{F}$

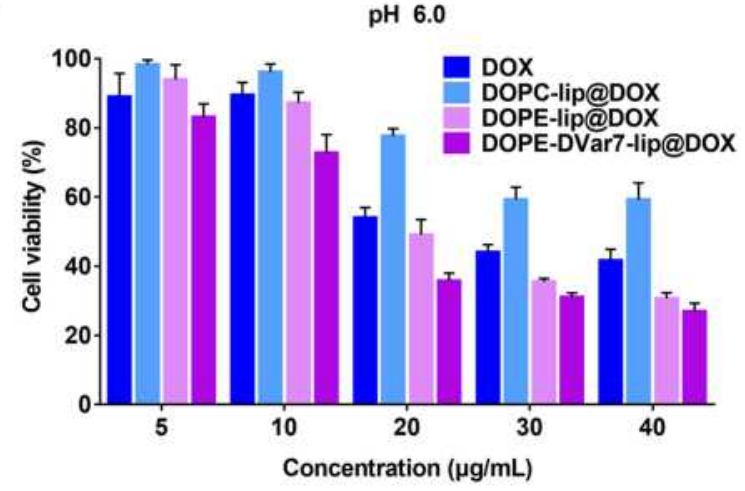

Figure 3 Cellular uptake and cytotoxicity of liposomes in tumor cells. (A) Cellular uptake of Cy5.5-loaded liposomes in MDA-MB-435S cells. (B) Cellular uptake of Cy5.5-loaded liposomes in Hela cells (mean \pm SEM, $n=3$ ). (C) CLSM images of MDA-MB-435S cells incubated with free DOX and DOX-loaded liposomes for I h at $37{ }^{\circ} \mathrm{C}$. The lysosomes were stained by LysoTracker Red and the nuclei were stained with Hoechst 33342. (D) Quantitative analysis of the uptake of free DOX and DOX-loaded liposomes (mean \pm SEM, $n=3$ ). (E and $\mathbf{F})$ Cytotoxicity of different concentrations of DOX-loaded liposomes after incubating MDA-MB-435S cells for $4 \mathrm{~h}$ at $\mathrm{pH} 7.4$ (E) or for $4 \mathrm{~h}$ at $\mathrm{pH} 6.0(\mathbf{F})($ mean $\pm \mathrm{SEM}, \mathrm{n}=6)$. $* * \mathrm{P}<0.0 \mathrm{I}$, $* * * \mathrm{P}<0.00 \mathrm{I}, * * * * \mathrm{P}<0.000 \mathrm{I}$.

Next, the change of liposome uptake in tumor cells over time was evaluated. In the first three time points (1, 2 , and $4 \mathrm{~h}$ ), the cellular uptake of the three liposomes increased with time, and the change in uptake was not notable after $4 \mathrm{~h}$. Thus, we believe that liposomes were mainly taken into the cells within the first $4 \mathrm{~h}$ and prolonged the incubation time will not further increase the uptake of liposomes (Supplementary Figure S6).

\section{In vitro Cell Toxicity}

To verify the therapeutic effect of liposomes in vitro, the toxicity of blank liposomes and DOX-loaded liposomes under different $\mathrm{pH}$ conditions was determined by MTT assay. After tumor cells were co-incubated with blank phospholipid for $48 \mathrm{~h}$, the cell survival rate remained above $90 \%$, even though the phospholipid concentration was as high as $1000 \mathrm{nmol} / \mathrm{mL}$ (Supplementary Figure S7), 
which indicated the good biocompatibility of the liposomes. Free DOX and three DOX liposomes showed concentration-dependent cytotoxic effects on MDA-MB-435S (Figure 3E and F). Compared with free DOX, DOPClip@DOX had a weaker cytotoxic effect on cells, probably because $\mathrm{DOX} \cdot \mathrm{HCl}$ is a small molecule that plays a direct role after entering cells, while DOPC-lip@DOX releases DOX slowly after entering cells through endocytosis and cannot reach a high concentration quickly. The $\mathrm{IC}_{50}$ of DOPE-lip@DOX was $27.85 \mu \mathrm{g} / \mathrm{mL}$ at pH 7.4, which was slightly improved at $\mathrm{pH} 6.0(24.09 \mu \mathrm{g} / \mathrm{mL})$. This indicated that the extracellular $\mathrm{pH} 6.0$ acidic microenvironment could not significantly improve the killing effect of monoacid-sensitive liposome DOPE-lip@DOX on tumor cells. After all, it is usually effective in lysosomes (pH 5.0). ${ }^{16-19}$ For the dual pH-responsive liposome DOPE-DVar7-lip@DOX, the $\mathrm{IC}_{50}$ values for $\mathrm{pH} 6.0$ $(16.37 \mu \mathrm{g} / \mathrm{mL})$ were significantly improved than that of $\mathrm{pH} 7.4(24.09 \mu \mathrm{g} / \mathrm{mL})$, indicating that the cell-killing effect of dual $\mathrm{pH}$-responsive liposomes was significantly enhanced at $\mathrm{pH}$ 6.0. The acidic microenvironment increases the $\mathrm{pH}$ gradient inside and outside the cells, so the DVar7 could be reconstructed and inserted itself into the cell membrane under acidic conditions to promote the fusion between liposomes and tumor cell membranes. The dual $\mathrm{pH}$-responsive liposomes allowed more liposomes to enter tumor cells and release doxorubicin rapidly. This led to a high concentration of drug inside tumor cells, and the achievement of the better anticancer effect.

\section{Small Animal in vivo Fluorescence Imaging}

As a truncated pHLIP, Var7 has better overall water solubility compared to full-length WT-pHLIP, and more appropriate for imaging purpose. Moreover, DVar7 can reduce degradation by enzymes, remain stable in vivo to respond to acidic microenvironments. We have previously used DVar7 for tumor imaging studies, and the results showed that DVar7 is still acid-sensitive, and the SPECT imaging with ${ }^{99 \mathrm{~m}}$ Tc-labeled DVar7 can clearly visualize the acidic tumors. ${ }^{37}$ Here, to study the in vivo behaviors of DOXliposomes, the near-infrared fluorescent dye Cy5.5 was encapsulated into liposomes (Cy5.5-liposomes) for fluorescence imaging in tumor-bearing animals. Near-infrared fluorescence imaging was performed at 4, 24, 48, and 72 $\mathrm{h}$ after injection of three fluorescent liposomes, and another group of mice was injected with high-concentration glucose 45 min before administration of DOPEDVar7-lip@Cy5.5 liposomes (Figure 4A). The fluorescence intensity of the tumor sites was quantitatively analyzed and normalized with the contralateral hind leg muscles as a background (Figure 4B-D). Compared with the DOPC-lip, DOPE-lip had higher accumulation in the tumors at 4 and $24 \mathrm{~h}(4 \mathrm{~h}: 0.72 \pm 0.01$ vs $1.12 \pm 0.03,24 \mathrm{~h}$ : $0.84 \pm 0.02$ vs $\left.1.23 \pm 0.05, \mathrm{n}=3,{ }^{* *} \mathrm{p}<0.01,{ }^{* * *} \mathrm{p}<0.001\right)$. The DOPE-DVar7-lip showed higher tumor uptake than DOPE-lip at $48 \mathrm{~h}$ and $72 \mathrm{~h}(48 \mathrm{~h}: 1.21 \pm 0.06$ vs $0.83 \pm$ $0.07,72 \mathrm{~h}: 1.06 \pm 0.01$ vs $0.60 \pm 0.06, \mathrm{n}=3,{ }^{*} \mathrm{p}<0.05$, $* * \mathrm{p}<0.01)$. For the group of DOPE-DVar7-lip with the injection of high concentration of glucose, the $\mathrm{pH}$ of the tumor microenvironment was acidified, which significantly increased tumor uptake than the DOPE-DVar7-lip treatment alone at $4 \mathrm{~h}(1.93 \pm 0.08$ vs $1.22 \pm 0.07, \mathrm{n}=3$, $\left.{ }^{* *} \mathrm{p}<0.01\right)$, and the high uptake lasted until $72 \mathrm{~h}$ after administration ( $48 \mathrm{~h}: 1.47 \pm 0.06$ vs $1.21 \pm 0.06,72 \mathrm{~h}$ : $1.51 \pm 0.01$ vs $\left.1.06 \pm 0.01, \mathrm{n}=3 .{ }^{*} \mathrm{p}<0.05, * * * \mathrm{p}<0.001\right)$. Near-infrared fluorescence imaging experiments demonstrated the tumor-targeting advantages of dual pH-responsive liposomes.

Previous studies have shown that the injection of glucose can modestly increase the $\mathrm{pH}$ gradient inside and outside tumor cells. Forty-five minutes after injection of glucose, the $\mathrm{pH}$ gradient of tumor cells can turn to 0.61 , with a pHe of $6.5 .^{38-40}$ In this study, the tumor delivery efficiency of dual $\mathrm{pH}$-responsive liposomes was further enhanced by regulating the tumor microenvironment with glucose injection.

\section{Dual $\mathrm{pH}$-Responsive DOX Liposome for Tumor-Targeted Therapy}

The anticancer effect of the doxorubicin liposome was evaluated in a mouse model subcutaneously inoculated with MDA-MB-435S cells. There was a significant difference between the free doxorubicin and the DOPClip@DOX group on the 11th day of treatment, with tumor volumes of $196.10 \pm 17.06 \mathrm{~mm}^{3}$ vs $154.50 \pm$ $6.35 \mathrm{~mm}^{3} \quad\left({ }^{*} \mathrm{p}<0.05\right), \quad$ respectively (Figure $\left.5 \mathrm{~A}\right)$. Compared with free doxorubicin, the long-circulating DOX liposome avoided direct contact between doxorubicin and the extracellular acidic microenvironment, reduced the loss of DOX in the extracellular environment and its distribution in normal tissues and organs. Therefore, the therapeutic effect was improved. The significant difference in tumor volume between the DOPClip@DOX group and the DOPE-lip@DOX group appeared on 4th day $\left(102.00 \pm 4.72 \mathrm{~mm}^{3}\right.$ vs $73.40 \pm$ 
A

$$
\text { ڤొ }
$$

ํㅜㄹ

$4 \mathrm{~h}$

$24 \mathrm{~h}$

$48 \mathrm{~h}$

$72 \mathrm{~h}$

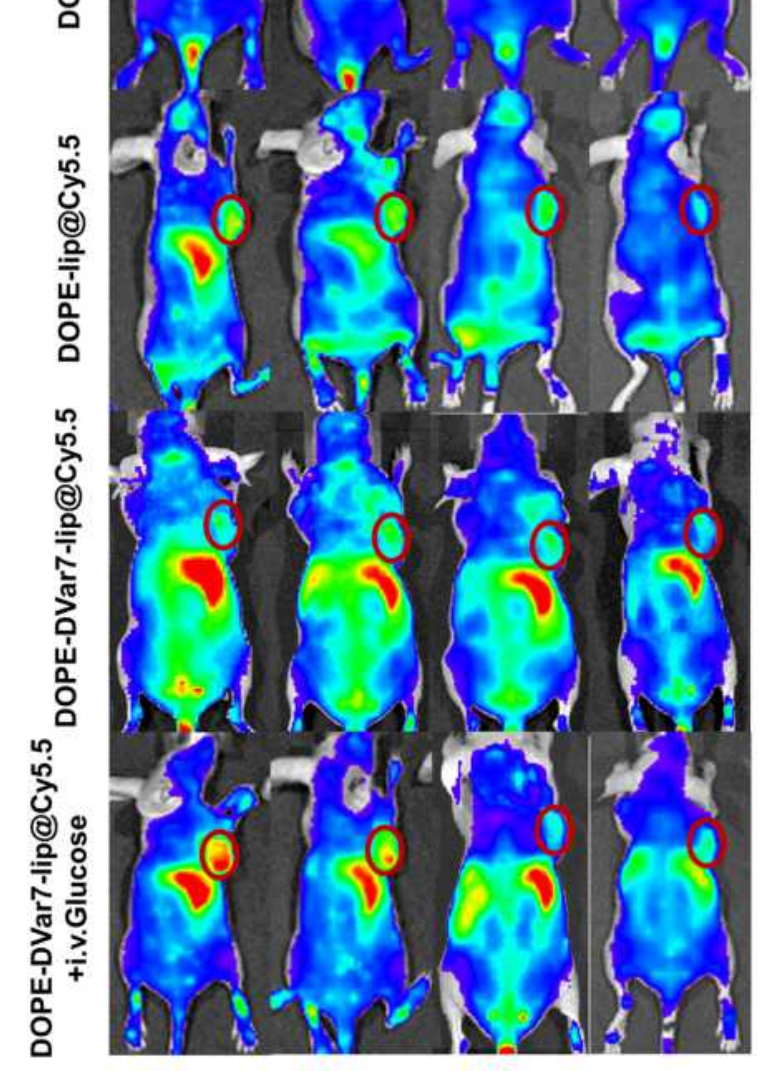

B

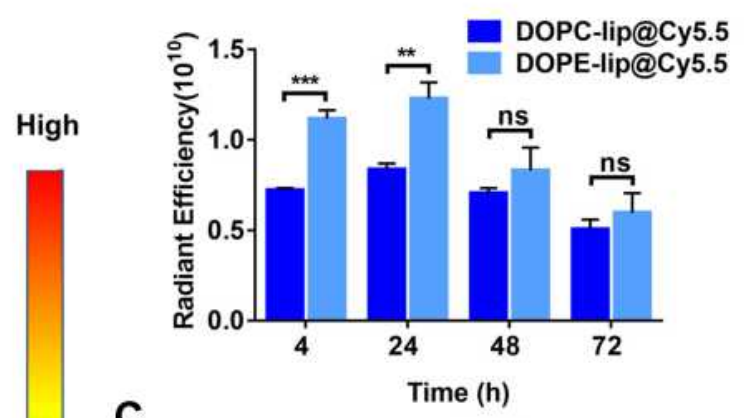

C
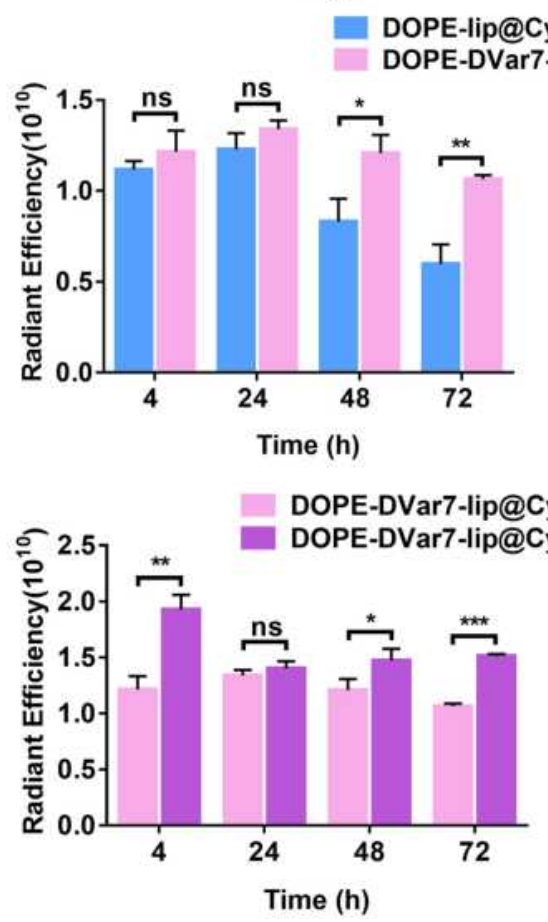

Figure 4 In vivo tumor-targeting ability. (A) Representative fluorescence images of MDA-MB-435S tumor-bearing BALB/c mice at 4, 24, 48, and 72 h after intravenous injection with DOPC-lip@Cy5.5, DOPE-lip@Cy5.5, DOPE-DVar7-lip@Cy5.5, and DOPE-DVar7-lip@Cy5.5 plus glucose injection. (B-D) Fluorescence intensity of the Cy5.5 signal between groups of DOPC-lip@Cy5.5 and DOPE-lip@Cy5.5 (B), DOPE-lip@Cy5.5 and DOPE-DVar7-lip@Cy5.5 (C), DOPE-DVar7-lip@Cy5.5 and DOPEDVar7-lip@Cy5.5 plus glucose injection (D) (mean \pm SEM, $n=3,{ }^{*}<0.05$, **p $<0.01$, *** ${ }^{*}<0.00$ I).

$\left.4.83 \mathrm{~mm}^{3},{ }^{*} \mathrm{p}<0.05\right)$. The DOPE-lip@DOX group and the DOPE-DVar7-lip@DOX group were significantly different, with tumor volumes of $116.50 \pm 9.22 \mathrm{~mm}^{3}$ vs $86.73 \pm$ $6.51 \mathrm{~mm}^{3}(* \mathrm{p}<0.05)$ on the 15 th day of treatment. The DOPE-DVar7-lip@DOX group and the acidified microenvironment DOPE-DVar7-lip@DOX group showed a significant difference on the 3rd day of treatment, with volumes of $73.69 \pm 5.48 \mathrm{~mm}^{3}$ vs $52.31 \pm 4.95 \mathrm{~mm}^{3}$ $\left({ }^{*} \mathrm{p}<0.05\right)$. There was no significant difference in the DOPC-lip@DOX groups with or without acidified microenvironment throughout the treatment, indicating that the $\mathrm{pH}$ of the tumor microenvironment had no effect on the efficacy of non-acid-responsive liposomes and that glucose injection itself has no therapeutic effect. During the entire treatment period, the body weight of all groups fluctuated slightly, and no weight loss exceeded $20 \%$ (Figure S8). At the end of the treatment, we excised and collected the tumor tissues of mice (Figure 5B) and compared the difference between the tumor weights of the groups (Figure 5C). As a result, the DOPE-DVar7lip@DOX group showed the best therapeutic efficacy (n $=6$ ), adding glucose to increase the acidity of the tumor microenvironment significantly improved the curative effect. The mouse tumor tissue and organs, including heart, liver, spleen, lung, and kidney, were stained with H\&E to observe histopathological changes. As shown in Figure S9, there were no morphological changes in the heart, liver, spleen, lung, and kidney of each group, which 


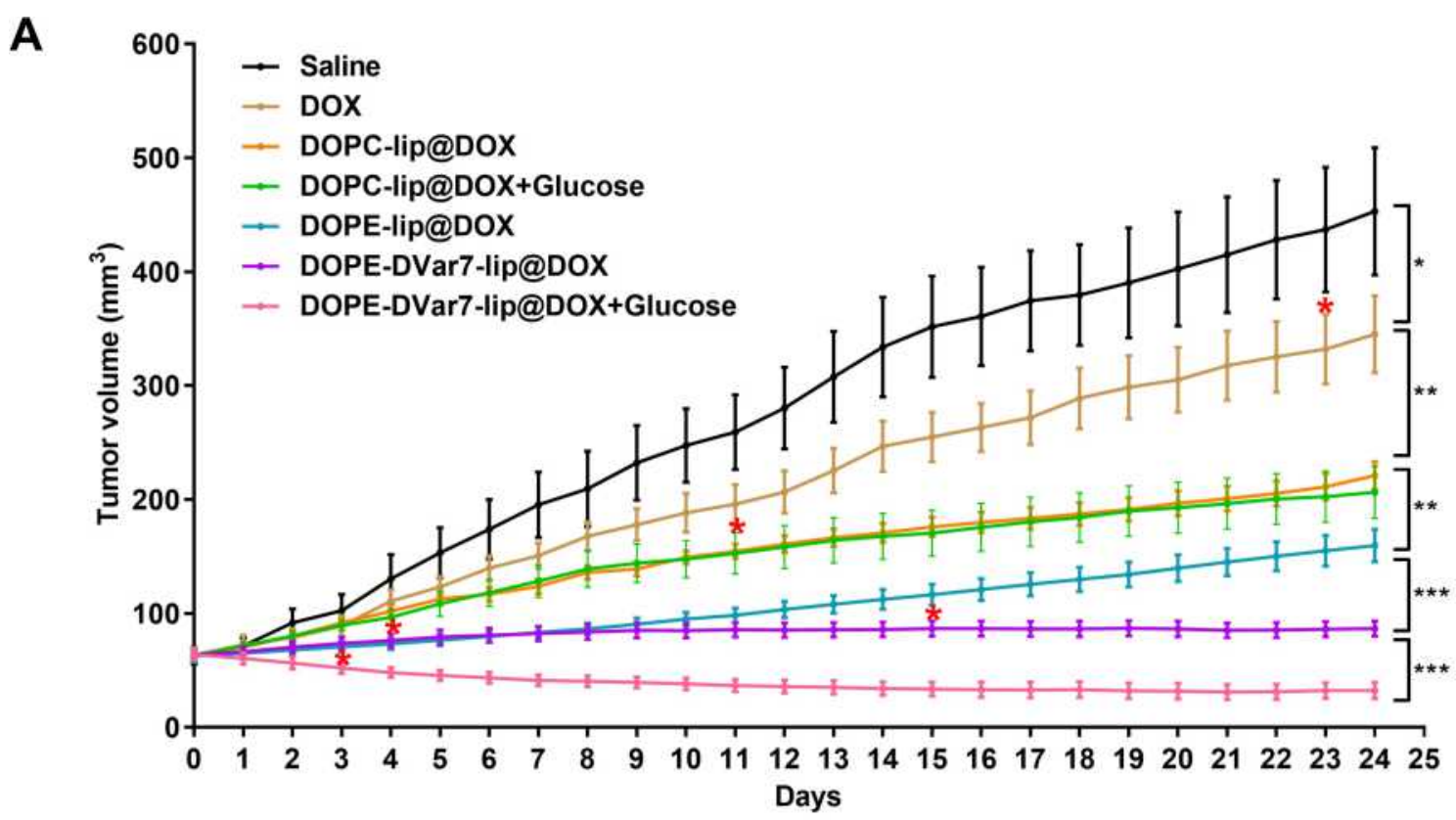

B

Saline

Dox

DOPC-lip@DOX

DOPC-lip@DOX +Glucose

DOPE-lip@DOX

DOPE-DVar7-lip @DOX

DOPE-DVar7-lip @DOX+Glucose

D

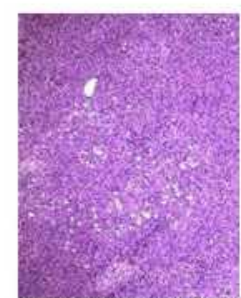

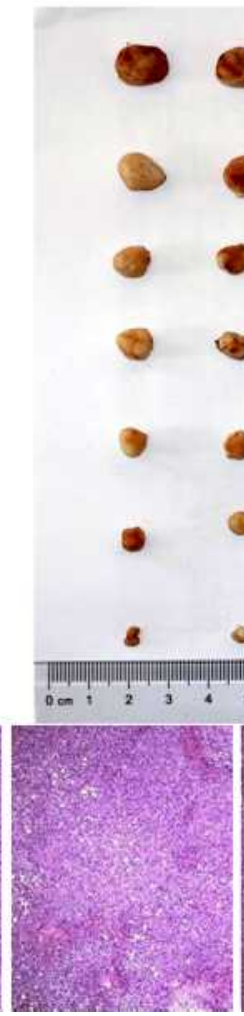
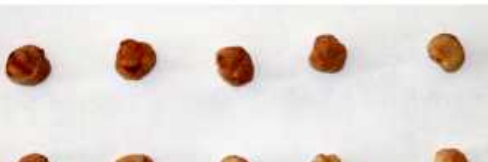

3
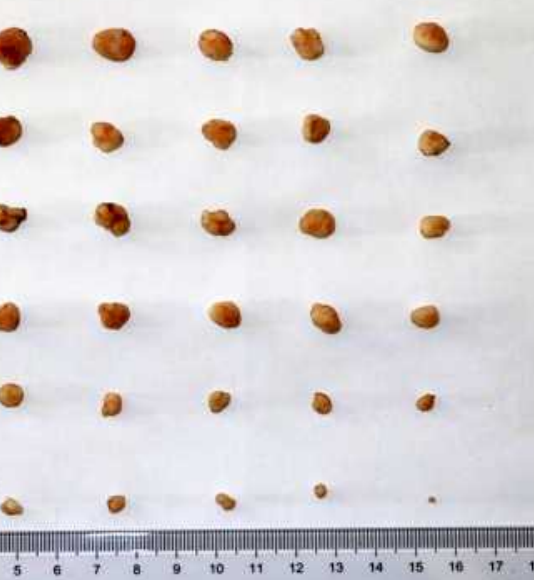

C
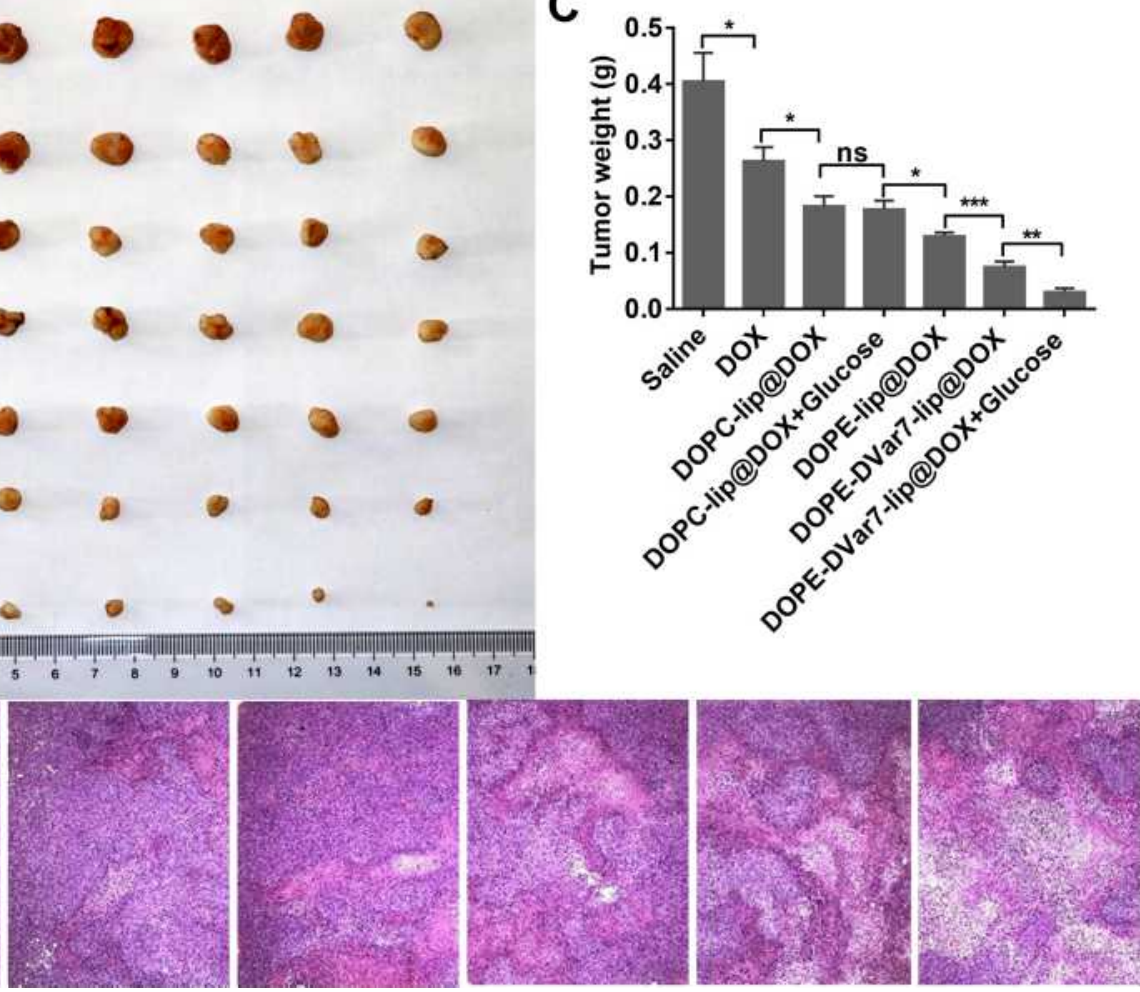

Figure 5 Antitumor effect in vivo. Saline, free DOX, DOPC-lip@DOX, DOPE-lip@DOX, DOPE-DVar7-lip@DOX, a combination of glucose and DOPC-lip@DOX, and a combination of glucose and DOPE-DVar7-lip@DOX were administered to MDA-MB-435S tumor-bearing mice via tail vein injections every 4 days at a DOX dose of 10 mg/ kg. Saline was used as a negative control, and the injection volume was $0.1 \mathrm{~mL}$. The treatment of glucose was given 45 minutes after liposome injection. (A) Tumor volume changes of MDA-MB-435S tumor-bearing mice. $\left(n=6,{ }^{*}<0.05\right)$. (B) Picture of tumor tissues collected from MDA-MB-435S tumor-bearing mice on day 24. (C) A comparison of the final tumor weights of different groups was performed on 24 th day (mean \pm SEM, $n=6, *_{p}<0.05, * * p<0.01$, *** $p<0.00 I$ ). (D) H\&E analysis of tumor tissues.

indicated that the dose of the drug used in the experiment was non-toxic. By comparing the H\&E staining results of the tumors (Figure 5D), the DOPE-lip@DOX, DOPEDVar7-lip@DOX and DOPE-DVar7-lip@DOX+glucose treatment groups had notable tumor necrosis. Among them, the tumor necrosis of the DOPE-DVar7-lip@DOX + glucose treatment group was the most severe, indicating that it had the best tumor suppressive efficacy. ${ }^{41}$ 
Tumor drug resistance is one of the main reasons for the failure of chemotherapy and molecularly targeted drug therapy ${ }^{42,43}$ Low extracellular $\mathrm{pH}(\mathrm{pHe})$ in tumor cells creates an ion-trapping phenomenon known as a physiological drug barrier that inhibits the use of weak base chemotherapeutic drugs. ${ }^{38,44-46}$ Because a lot of chemotherapy drugs are alkaline, the clinical effect of chemotherapy is greatly affected. Here, we prepared the dual $\mathrm{pH}$-responsive liposomes to take advantage of the nature of the acidic tumor microenvironment. Compared with traditional liposomes, the dual $\mathrm{pH}$-responsive liposomes have remarkable advantages in tumor targeted treatment and overcoming doxorubicin resistance. Moreover, the glucose injection, which acidified the tumor microenvironment, further improved the therapeutic effect. The combination of dual $\mathrm{pH}$-responsive liposomes and $\mathrm{pH}$ adjustment provides ideas for clinical optimization of therapeutic liposomes and has great potential for clinical improvement of drug resistance. ${ }^{47}$ Since MDA-MB-435S is not a highly malignant tumor model, if it is replaced with a more malignant tumor model, dual $\mathrm{pH}$ responsive liposomes may be able to show more therapeutic advantages. ${ }^{48}$ Studies have found that, besides injecting high concentrations of glucose, the tumor microenvironment can also be acidified by heating the tumor site. Further research is needed to determine which method is more effective in tumor treatment.

\section{Conclusions}

In summary, a novel dual $\mathrm{pH}$-responsive DOX-encapsulated liposome was prepared, and a solution to enhance the therapeutic effect of $\mathrm{pH}$-responsive liposomes by regulating the $\mathrm{pH}$ value of tumor microenvironment was provided. In the acidic tumor microenvironment, the acidsensitive peptide DVar7 was allosterically inserted into the tumor cell membrane, which enhanced the tumor uptake of liposomes and prolonged the retention time of liposomes in tumors. At the same time, through acid-sensitive DOPE, acid-controlled release of DOX in lysosomes of tumor cells was accelerated. Therefore, the dual $\mathrm{pH}$-responsive DOXencapsulated liposome DOPE-DVar7-lip@DOX showed significantly enhanced treatment efficacy than traditional liposomes and mono pH-responsive liposomes. In addition, regulating the $\mathrm{pH}$ value of TME by injecting the clinically implementable glucose could further improve the therapeutic effect of the dual $\mathrm{pH}$-responsive liposomes, which possesses great potential for improving drug resistance in clinical practice.

\section{Acknowledgments}

This research was supported by National Natural Science Foundation of China (NSFC) projects $(81630045,81971676$, 81571727, and 81927802), and Strategic Priority Research Program of the Chinese Academy of Sciences (XDA12020110), the Youth Innovation Promotion Association of Chinese Academy of Sciences (YIPACAS) project (YIPA2016090).

\section{Disclosure}

The authors declared no financial or nonfinancial conflicts of interest for this work.

\section{References}

1. Nagelkerke A, Bussink J, Rowan AE, Span PN. The mechanical microenvironment in cancer: how physics affects tumours. Semin Cancer Biol. 2015;35:62-70. doi:10.1016/j.semcancer.2015.09.001

2. Marchiq I, Pouyssegur J. Hypoxia, cancer metabolism and the therapeutic benefit of targeting lactate/H(+) symporters. J Mol Med. 2016;94(2):155-171. doi:10.1007/s00109-015-1307-x

3. Feng LZ, Dong ZL, Tao DL, Zhang YC, Liu Z. The acidic tumor microenvironment: a target for smart cancer nano-theranostics. Natl Sci Rev. 2018;5(2):269-286. doi:10.1093/nsr/nwx062

4. Ma X, Li X, Shi J, et al. Host-guest polypyrrole nanocomplex for three-stimuli-responsive drug delivery and imaging-guided chemophotothermal synergetic therapy of refractory thyroid cancer. Adv Healthcare Mater. 2019;8(17):1900661.

5. Li H, Krstin S, Wang S, Wink M. Capsaicin and Piperine Can Overcome Multidrug Resistance in Cancer Cells to Doxorubicin. Molecules. 2018;23(3):557.

6. Xia Y, Fang M, Dong J, et al. pH sensitive liposomes delivering tariquidar and doxorubicin to overcome multidrug resistance of resistant ovarian cancer cells. Colloids Surf B Biointerfaces. 2018;170:514-520. doi:10.1016/j.colsurfb.2018.06.055

7. Shi M, Zhang J, Li X, et al. Mitochondria-targeted delivery of doxorubicin to enhance antitumor activity with HER-2 peptide-mediated multifunctional $\mathrm{pH}$-sensitive DQAsomes. Int J Nanomedicine. 2018;13:4209-4226. doi:10.2147/IJN.S163858

8. Sun D, Ding J, Xiao C, Chen J, Zhuang X, Chen X. pH-responsive reversible pegylation improves performance of antineoplastic agent. Advanced Healthcare Materials. 2015;4(6):844-855. doi:10.1002/ adhm.201400736

9. Lu S, Bennett WFD, Ding Y, et al. Design and characterization of a multifunctional ph-triggered peptide $\mathrm{c} 8$ for selective anticancer activity. Advanced Healthcare Materials. 2015;4(17):2709-2718. doi:10.1002/adhm.201500636

10. Vander Heiden MG, Cantley LC, Thompson CB. Understanding the Warburg effect: the metabolic requirements of cell proliferation. Science. 2009;324(5930):1029-1033. doi:10.1126/science.1160809

11. Abri Aghdam M, Bagheri R, Mosafer J, et al. Recent advances on thermosensitive and $\mathrm{pH}$-sensitive liposomes employed in controlled release. J Control Release. 2019;315:1-22.

12. Paliwal SR, Paliwal R, Vyas SP. A review of mechanistic insight and application of $\mathrm{pH}$-sensitive liposomes in drug delivery. Drug Deliv. 2015;22(3):231-242. doi:10.3109/10717544.2014.882469

13. Heidarli E, Dadashzadeh S, Haeri A. State of the Art of stimuli-responsive liposomes for cancer therapy. Iran J Pharm Res. 2017;16(4):1273-1304. 
14. Wang J, MacEwan SR, Chilkoti A. Quantitative mapping of the spatial distribution of nanoparticles in endo-lysosomes by local $\mathrm{pH}$. Nano Lett. 2017;17(2):1226-1232. doi:10.1021/acs.nanolett.6b05041

15. Rehman AU, Omran Z, Anton H, et al. Development of doxorubicin hydrochloride loaded $\mathrm{pH}$-sensitive liposomes: investigation on the impact of chemical nature of lipids and liposome composition on pH-sensitivity. Eur J Pharm Biopharm. 2018;133:331-338. doi:10.1016/j.ejpb.2018.11.001

16. Xu H, Paxton JW, Wu Z. Development of long-circulating ph-sensitive liposomes to circumvent gemcitabine resistance in pancreatic cancer cells. Pharm Res. 2016;33(7):1628-1637. doi:10.1007/ s11095-016-1902-8

17. Hafez IM, Cullis PR. Cholesteryl hemisuccinate exhibits $\mathrm{pH}$ sensitive polymorphic phase behavior. Biochim Biophys Acta. 2000;1463 (1):107-114. doi:10.1016/S0005-2736(99)00186-8

18. Tila D, Ghasemi S, Yazdani-Arazi SN, Ghanbarzadeh S. Functional liposomes in the cancer-targeted drug delivery. J Biomater Appl. 2015;30(1):3-16. doi:10.1177/0885328215578111

19. Silva JO, Fernandes RS, Lopes SC, et al. pH-sensitive, long-circulating liposomes as an alternative tool to deliver doxorubicin into tumors: a Feasibility Animal Study. Mol Imaging Biol. 2016;18(6):898-904. doi:10.1007/s11307-016-0964-7

20. Faria M, Björnmalm M, Thurecht KJ, et al. Minimum information reporting in bio-nano experimental literature. Nat Nanotechnol. 2018;13(9):777-785. doi:10.1038/s41565-018-0246-4

21. Wilhelm S, Tavares AJ, Dai Q, et al. Analysis of nanoparticle delivery to tumours. Nat Rev Mater. 2016;1(5):16014. doi:10.1038/ natrevmats.2016.14

22. Martin FJ. Stealth liposome technology: an overview. Doxil Clin Ser. 1996;1:1-8.

23. Immordino ML, Dosio F, Cattel L. Stealth liposomes: review of the basic science, rationale, and clinical applications, existing and potential. Int J Nanomedicine. 2006;1(3):297-315.

24. Guo J, Gao X, Su L, et al. Aptamer-functionalized PEG-PLGA nanoparticles for enhanced anti-glioma drug delivery. Biomaterials. 2011;32(31):8010-8020. doi:10.1016/j.biomaterials.2011.07.004

25. Guo Z, He B, Jin H, et al. Targeting efficiency of RGD-modified nanocarriers with different ligand intervals in response to integrin alphavbeta3 clustering. Biomaterials. 2014;35(23):6106-6117. doi:10.1016/j.biomaterials.2014.04.031

26. Ruan S, Yuan M, Zhang L, et al. Tumor microenvironment sensitive doxorubicin delivery and release to glioma using angiopep-2 decorated gold nanoparticles. Biomaterials. 2015;37:425-435. doi:10.1016/j.biomaterials.2014.10.007

27. Dagogo-Jack I, Shaw AT. Tumour heterogeneity and resistance to cancer therapies. Nat Rev Clin Oncol. 2018;15(2):81-94. doi:10.1038/nrclinonc.2017.166

28. Reina-Campos M, Moscat J, Diaz-Meco M. Metabolism shapes the tumor microenvironment. Curr Opin Cell Biol. 2017;48:47-53. doi:10.1016/j.ceb.2017.05.006

29. Andreev OA, Engelman DM, Reshetnyak YK. Targeting acidic diseased tissue: new technology based on use of the $\mathrm{pH}$ (Low) Insertion Peptide (pHLIP). Chim Oggi. 2009;27(2):34-37.

30. Andreev OA, Engelman DM, Reshetnyak YK. Targeting diseased tissues by pHLIP insertion at low cell surface pH. Front Physiol. 2014;5:97. doi:10.3389/fphys.2014.00097

31. Andreev OA, Engelman DM, Reshetnyak YK. pH-sensitive membrane peptides (pHLIPs) as a novel class of delivery agents. $\mathrm{Mol} \mathrm{Membr}$ Biol. 2010;27(7):341-352. doi:10.3109/09687688.2010.509285
32. Weerakkody D, Moshnikova A, Thakur MS, et al. Family of $\mathrm{pH}$ (low) insertion peptides for tumor targeting. Proc Natl Acad Sci U S A. 2013;110(15):5834-5839. doi:10.1073/pnas.1303708110

33. Rinaldi F, Hanieh PN, Del Favero E, et al. Decoration of Nanovesicles with $\mathrm{pH}$ (Low) Insertion Peptide (pHLIP) for Targeted Delivery. Nanoscale Res Lett. 2018;13(1):391. doi:10.1186/s11671-018-2807-8

34. Yao L, Daniels J, Wijesinghe D, Andreev OA, Reshetnyak YK. pHLIP(R)-mediated delivery of PEGylated liposomes to cancer cells. J Control Release. 2013;167(3):228-237. doi:10.1016/j. jconrel.2013.01.037

35. Bhujwalla ZM, Aboagye EO, Gillies RJ, Chacko VP, Mendola CE, Backer JM. Nm23-transfected MDA-mB-435 human breast carcinoma cells form tumors with altered phospholipid metabolism and $\mathrm{pH}$ : a 31P nuclear magnetic resonance study in vivo and in vitro. Magn Reson Med. 1999;41(5):897-903. doi:10.1002/(SICI)15222594(199905)41:5<897::AID-MRM7>3.0.CO;2-T

36. Carafa M, Di Marzio L, Marianecci C, et al. Designing novel pH-sensitive non-phospholipid vesicle: characterization and cell interaction. Eur J Pharm Sci. 2006;28(5):385-393. doi:10.1016/j.ejps.2006.04.009

37. Shi J, Yang L, Zhai L, et al. NanoScan SPECT/CT Imaging of Tumor Acidic Microenvironment with 99mTc-labeled A novel ph low insertion peptide. Mol Imaging Biol. 2016;18(Suppl 1):S1-S1553.

38. Gerweck LE, Vijayappa S, Kozin S. Tumor $\mathrm{pH}$ controls the in vivo efficacy of weak acid and base chemotherapeutics. Mol Cancer Ther. 2006;5(5):1275-1279. doi:10.1158/1535-7163.MCT-06-0024

39. Zhou R, Bansal N, Leeper DB, Glickson JD. Intracellular acidification of human melanoma xenografts by the respiratory inhibitor m-iodobenzylguanidine plus hyperglycemia: a 31P magnetic resonance spectroscopy study. Cancer Res. 2000;60(13):3532-3536.

40. Kozin SV, Shkarin P, Gerweck LE. The cell transmembrane $\mathrm{pH}$ gradient in tumors enhances cytotoxicity of specific weak acid chemotherapeutics. Cancer Res. 2001;61(12):4740-4743.

41. Wijesinghe D, Arachchige MC, Lu A, Reshetnyak YK, Andreev OA. $\mathrm{pH}$ dependent transfer of nano-pores into membrane of cancer cells to induce apoptosis. Sci Rep. 2013;3:3560. doi:10.1038/srep03560

42. Gottesman MM. Mechanisms of cancer drug resistance. Annu Rev Med. 2002;53(1):615-627. doi:10.1146/annurev.med.53.082901.103929

43. Justus CR, Dong L, Yang LV. Acidic tumor microenvironment and pH-sensing G protein-coupled receptors. Front Physiol. 2013;4:354. doi:10.3389/fphys.2013.00354

44. Raghunand N, Gillies RJ. pH and drug resistance in tumors. Drug Resist Updates. 2000;3(1):39-47. doi:10.1054/drup.2000.0119

45. Raghunand N, Mahoney BP, Gillies RJ. Tumor acidity, ion trapping and chemotherapeutics. Biochem Pharmacol. 2003;66(7):1219-1229. doi:10.1016/S0006-2952(03)00468-4

46. Gerweck LE, Kozin SV, Stocks SJ. The pH partition theory predicts the accumulation and toxicity of doxorubicin in normal and low-pHadapted cells. Br J Cancer. 1999;79(5-6):838-842.

47. Liu J, Huang Y, Kumar A, et al. pH-sensitive nano-systems for drug delivery in cancer therapy. Biotechnol Adv. 2014;32(4):693-710. doi:10.1016/j.biotechadv.2013.11.009

48. Anderson M, Moshnikova A, Engelman DM, Reshetnyak YK, Andreev OA. Probe for the measurement of cell surface $\mathrm{pH}$ in vivo and ex vivo. Proc Natl Acad Sci U S A. 2016;113(29):8177-8181. doi:10.1073/pnas. 1608247113 


\section{Publish your work in this journal}

The International Journal of Nanomedicine is an international, peerreviewed journal focusing on the application of nanotechnology in diagnostics, therapeutics, and drug delivery systems throughout the biomedical field. This journal is indexed on PubMed Central, MedLine, CAS, SciSearch ${ }^{\mathbb{R}}$, Current Contents ${ }^{\mathbb{B}} /$ Clinical Medicine,
Journal Citation Reports/Science Edition, EMBase, Scopus and the Elsevier Bibliographic databases. The manuscript management system is completely online and includes a very quick and fair peer-review system, which is all easy to use. Visit http://www.dovepress.com/ testimonials.php to read real quotes from published authors.

Submit your manuscript here: https://www.dovepress.com/international-journal-of-nanomedicine-journal 